\title{
Ensino de Programação para Crianças através de Práticas Colaborativas nas Escolas
}

\author{
Paulo Silas Severo de Souza, Jaline Gonçalves Mombach \\ ${ }^{1}$ Instituto Federal de Educação, Ciência e Tecnologia \\ Farroupilha (IFFarroupilha) - Campus Alegrete \\ Caixa Postal 118 - 97.555-000 - Alegrete - RS - Brazil \\ paulo.severo.souza@outlook.com, jaline.mombach@iffarroupilha.edu.br
}

\begin{abstract}
This paper presents experience report on an extension project for teaching programming to children from public schools. The methodology that guides the work is based on Participatory Design and Collaborative Practices using "Scratch tool". We conclude that this practice had good results and can contribute for the development of logical reasoning, requiring students the ability to solve problems and challenges.

Resumo. Este artigo apresenta relato de experiência de um projeto de extensão para ensino de programação a crianças de escolas públicas. A metodologia que guia o trabalho é baseada no Design Participativo e Práticas Colaborativas usando a ferramenta Scratch. Conclui-se que esta prática teve bons resultados e pode contribuir para desenvolvimento do raciocínio lógico, exigindo dos estudantes habilidades para resolução de problemas e desafios.
\end{abstract}

\section{Introdução}

O processo de ensino-aprendizagem apoiado pelo computador e demais recursos de TIC, se torna efetivo quando além de apenas manuseá-los, os alunos aprendem a usar estas ferramentas em situações que promovem a construção do conhecimento e a proficiência digital (NOBRE; SOUSA; NOBRE, 2015).

Estudos comprovam o quanto é relevante ensinar computação desde a educação básica. Von Wangenheim, Nunes e Santos (2014) descrevem que esta atividade pode aumentar a criatividade dos alunos, permitindo domínio consciente da tecnologia e impactando de forma positiva no ambiente ao seu redor. Promover a discussão nas escolas contribui para o crescimento da força de trabalho e consequentemente, capacita para a projeção de novos sistemas de computação para melhorar a qualidade de vida da população. Os autores também destacam que independente da carreira profissional a ser escolhida, aprender a aplicar as novas tecnologias para resolução de problemas, auxilia na inserção desses indivíduos no mercado de trabalho, pois entendendo o conceito amplo de computação, podem se tornar profissionais mais produtivos e competitivos em suas áreas.

Assim, o pensamento computacional e a prática de programação surgem como aliados importantes para desenvolver a habilidade de resolução de problemas (CAMPOS et al., 2014). Existem algumas opções de ferramentas educacionais, como as disponibilizadas pela Code.org ${ }^{1}$, uma organização sem fins lucrativos que através do apoio de personalidades do mundo tecnológico como Bill Gates e Mark Zuckerberg, oferece atividades

\footnotetext{
${ }^{1}$ Disponível em $<\langle$ https://code.org $/\rangle>$.
} 
educativas sobre programação. Além destas, outra ferramenta conhecida é o Scratch ${ }^{2}$, uma linguagem de programação em blocos desenvolvida no Massachusetts Institute of Technology que é amplamente utilizada em escolas para desenvolver o pensamento computacional (RAMOS; TEIXEIRA, 2015).

Diante do exposto, este artigo descreve um relato de experiências obtidas com projeto de extensão para ensino de programação em escolas públicas da cidade de Alegrete, interior do Rio Grande do Sul. A prática teve como objetivo geral oferecer oficinas de programação para alunos do ensino fundamental de escolas públicas. Como objetivos específicos, fomentar interesse pelo curso técnico em informática entre estudantes do ensino fundamental, ensinar conceitos básicos da programação de computadores de forma lúdica e atrativa, e oportunizar o protagonismo em projetos de extensão a alunos do curso técnico e superior, permitindo compartilhar com a sociedade o conhecimento adquirido no curso.

O restante deste trabalho está organizado como segue. Na Seção 2 apresentase o referencial teórico-metodológico com as abordagens adotadas durante os encontros realizados nos laboratórios de informática das escolas, bem como as possibilidades da ferramenta Scratch. Diversos estudos adotam o ensino de programação na educação básica e por isso, práticas similares são descritas na Seção 3. A Seção 4 é reservada ao relato das experiências obtidas, incluindo de forma detalhada o perfil das crianças participantes e as atividades realizadas em cada encontro. Por fim, a Seção 5 discute as percepções das crianças e da equipe executora e discorre as considerações finais.

\section{Referencial Teórico-Metodológico}

Nesta Seção explana-se sobre os principais conceitos que envolvem a metodologia adotada, a abordagem baseada no Pensamento Computacional e Resolução de Problemas e Design Participativo com Práticas Colaborativas. Além disso, apresenta-se brevemente os principais recursos da ferramenta escolhida, o Scratch.

\subsection{Pensamento Computacional e Resolução de Problemas}

Conforme Furber (2012) pensamento computacional é o processo de reconhecimento de elementos da computação em diversos âmbitos da sociedade, assim como a aplicação de técnicas e ferramentas de Ciência da Computação no entendimento de processos e sistemas naturais e artificiais. Nesse sentido, Wing (2006) explica que pensamento computacional utiliza conceitos de Ciência da Computação na compreensão do comportamento humano, design de sistemas e resolução de problemas. Lee et al. (2011) explicam que o pensamento computacional pode ser aplicado em sala de aula através de atividades como construção de projetos de robótica ou desenvolvimento de jogos no ensino de abstrações, análises e processos de automação.

A aprendizagem baseada em resolução de problemas, por sua vez, é uma metodologia instrucionista que usa problemas reais para motivar a aprendizagem. Em um primeiro momento o problema a ser abordado é apresentado ao grupo de alunos, que recebem a liberdade de discutir, formular hipóteses e metas de aprendizado, visando solucionar o problema proposto (VIEIRA, 2014).

\footnotetext{
${ }^{2}$ Disponível em $<\langle$ https://scratch.mit.edu $/\rangle>$.
} 
Além disso, conforme as Diretrizes Curriculares Nacionais para os cursos de Graduação em Computação (BRASIL, 2012), o uso do pensamento computacional na educação básica auxilia na obtenção de recursos cognitivos que ampliam a capacidade de resolução de problemas.

\subsection{Design Participativo}

O Design Participativo é uma abordagem colaborativa que pode ser utilizada para diversos fins, como desenvolvimento de produtos, serviços ou sistemas, que fundamenta-se na participação de interessados na tomada de decisões (DUST; JONSDATTER, 2008). Esta metodologia promove a participação ativa dos usuários, ou seja, os participantes deixam de ser meros expectadores e passam a atuar como coautores, propondo atividades e até mesmo adaptações ao que estava previamente planejado.

Beynon-Davies (1998) explicam que o Design Participativo enfatiza a espontaneidade e a utilização de métodos colaborativos visando o aprendizado mútuo dos envolvidos para obtenção de resultados mais efetivos.

No contexto educacional, o Design Participativo pode ser utilizado para constatar as demandas dos alunos, possibilitando o desenvolvimento de atividades instigantes, através da interatividade (MOMBACH et al., 2010).

\subsubsection{Práticas Colaborativas}

Através de práticas colaborativas, educandos podem dividir tarefas, discutir sobre soluções eficazes e unir conhecimentos visando solucionar os problemas propostos. Nesse sentido, Ramos (2011) explica que esse tipo de atividade é extremamente benéfica aos alunos, pois possibilita a troca de conhecimento e favorece o desenvolvimento de habilidades sociais.

Além disso, trabalhar em grupo permite que alunos complementem seus conhecimentos, e através da troca de ideias tornem-se mais criativos. Nesse contexto, a tecnologia destaca-se por ampliar as oportunidades de colaboração através de computadores, dispositivos móveis e internet (LUCENA, 2012; FONSECA, 2013).

\section{Trabalhos Relacionados}

Diversos autores tem realizado trabalhos de inclusão tecnológica em escolas, com vista ao desenvolvimento do pensamento computacional. Alguns desses trabalhos são discutidos a seguir.

França e Amaral (2013) utilizaram o Scratch em uma oficina para alunos da educação básica. Os resultados mostraram que as crianças aprenderam diversos fundamentos de Ciência da Computação em um curto período de tempo, o que mostrou a eficácia da ferramenta na transmissão do pensamento computacional. Ramos e Teixeira (2015) ministraram um minicurso para difundir o pensamento computacional no ensino médio através do Scratch. No decorrer do projeto os alunos mostraram-se mais criativos e autônomos ante os desafios propostos. Assim, percebeu-se a relevância do uso de ferramentas tecnológicas no processo educacional. 
Rodriguez et al. (2015) relatam experiências obtidas em projeto que incluiu ferramentas digitais em escolas. Os alunos que participaram do projeto desenvolveram algoritmos usando o Scratch. Conforme os autores, observou-se que o pensamento computacional ajudou a ampliar a capacidade de resolução de problemas dos alunos através de atividades lúdicas. Mota et al. (2014) realizaram uma oficina de programação visando desenvolver a capacidade de resolução de problemas de alunos de escolas públicas. Utilizou-se o Scratch para desenvolver jogos que automatizaram a resolução de cálculos matemáticos. Após a oficina, os discentes demonstraram seu interesse em dar continuidade às atividades de programação.

Em suma, nota-se que a realização de projetos para ensino de programação nas escolas apresenta resultados promissores, principalmente pelo interesse demonstrado pelos alunos da rede pública. Porém, várias destas intervenções são realizadas em instituições federais de ensino, ou seja, os regentes das turmas não se apropriam das atividades desenvolvidas e muitas destas propostas são concluídas como ações pontuais, sem continuidade. Ademais, os relatos apresentados são contextualizados em escolas urbanas.

Logo, o que difere este trabalho dos demais é o fato dos alunos dos cursos de tecnologia se deslocarem até as escolas participantes, prepararem os laboratórios com a instalação da ferramenta e assim, fornecerem subsídio para que os professores possam dar seguimento ao trabalho desenvolvido com a turma, mesmo após a conclusão do projeto de extensão. Além disso, as duas escolas em que a proposta foi aplicada, incluindo uma na zona rural, possuíam laboratórios com máquinas obsoletas e algumas sem acesso à internet e/ou com velocidade lenta na conexão.

\section{Relato de Experiência}

Esta Seção apresenta o detalhamento das atividades planejadas, bem como o perfil dos participantes e descrição das tarefas de cada oficina.

\subsection{Contexto e Metodologia}

O projeto "Hora do Código" foi realizado com turmas do $4^{\circ}$ ano do ensino fundamental de duas escolas públicas de Alegrete - RS. A Escola Municipal Honório Lemes fica localizada em um bairro distante da zona central, já a Escola Estadual Barros Cassal é localizada na zona rural, há aproximadamente $40 \mathrm{~km}$ da cidade. Como já mencionado, as duas escolas possuíam laboratórios com máquinas desatualizadas, com pouca conectividade e com falta de suporte para manutenção. Conforme relato da comunidade, estas características contribuíam para subutilização dos espaços.

Os encontros ocorreram entre os meses de agosto e novembro de 2015, sendo seis encontros com duração de três horas em cada escola. Aproximadamente 32 crianças formaram o público-alvo do projeto. A equipe executora contemplou a professora coordenadora, dois estudantes do curso técnico em Informática e um acadêmico de Análise e Desenvolvimento de Sistemas. A Figura 1 apresenta as três ações principais do projeto: análise do perfil dos participantes, realização de atividades exploratórias e finalmente, a prática em oficinas com Scratch. Para o desenvolvimento do projeto selecionou-se alguns materiais que poderiam auxiliar no ensino de conceitos de programação e pensamento computacional:

- Jogos da Code.org: voltados ao desenvolvimento da capacidade lógica com desafios lúdicos propostos com personagens populares no público infantil. 


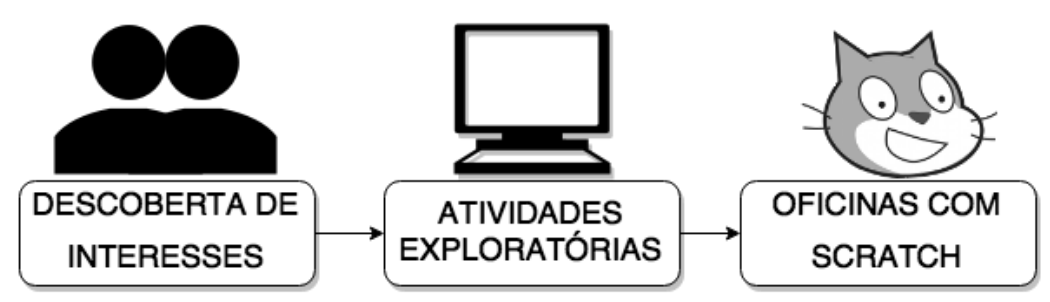

Figura 1. Principais ações planejadas.

- Desafios lógicos do Blockly ${ }^{3}$ : biblioteca da Google para ensino de programação que oferece diversas atividades educativas e permite a programação através de blocos que representam comandos e são disponibilizados off-line.

- Scratch: ferramenta desenvolvida no Massachusetts Institute of Technology (MIT) que visa auxiliar o aprendizado de computação através de um ambiente de programação com blocos que possibilitam alterar o ambiente, personagens e objetos da ferramenta, formando jogos e animações. Ressalta-se que há versão desta ferramenta disponibilizada off-line.

- Provas Canguru ${ }^{4}$ : avaliações da Associação Canguru Sem Fronteiras, criada em 1994, e que hoje é realizada em 52 países. Os desafios buscam apresentar o lado lúdico da matemática através de questões que unem raciocínio lógico com conceitos matemáticos.

\subsection{Primeiro e Segundo Encontro}

Ressalta-se que antes dos encontros, os estudantes proponentes visitaram as escolas e realizaram a instalação do Scratch nos computadores, além de conversar com os professores regentes das turmas.

No primeiro encontro, a equipe executora se apresentou e explicou a iniciativa. $\mathrm{Na}$ sequência, mostraram um vídeo motivacional do projeto Code.org sobre a importância de aprender programação. Após, as crianças foram incentivadas a visitar o site do Scratch e explorar as animações e jogos criados por outros usuários para que tivessem uma visão prática das atividades que poderiam ser desenvolvidas. Também, o site Hora do Código ${ }^{5}$ para escolherem desafios de lógica com personagens já conhecidos. A Figura 2 mostra que pelo número limitado de computadores e dificuldades de navegação na internet, o grupo de crianças da escola rural realizou a atividade em grupos.

Alguns alunos da escola rural destacaram-se por completar todos os níveis de jogos de lógica oferecidos. Na outra escola não havia conexão com a internet, então adotou-se os desafios do Blockly e também o carregamento manual de jogos e animações pré-selecionados do Scratch. Porém, em ambas escolas ao final do encontro as crianças mostraram-se entusiasmadas e perguntando quando seria o próximo encontro.

No segundo encontro, as crianças confeccionaram crachás para facilitar a comunicação entre os participantes. Além disso, a fim de descobrir os interesses do grupo e adaptar as próximas atividades, aplicou-se um questionário para analisar a familiaridade

\footnotetext{
${ }^{3}$ Disponível em $<\langle$ https://developers.google.com/blockly/ $\rangle$.

${ }^{4}$ Disponível em $<\langle$ http://www.cangurudematematicabrasil.com.br $\rangle>$.

${ }^{5}$ Disponível em $<\langle$ https://code.org/learn $\rangle$.
} 


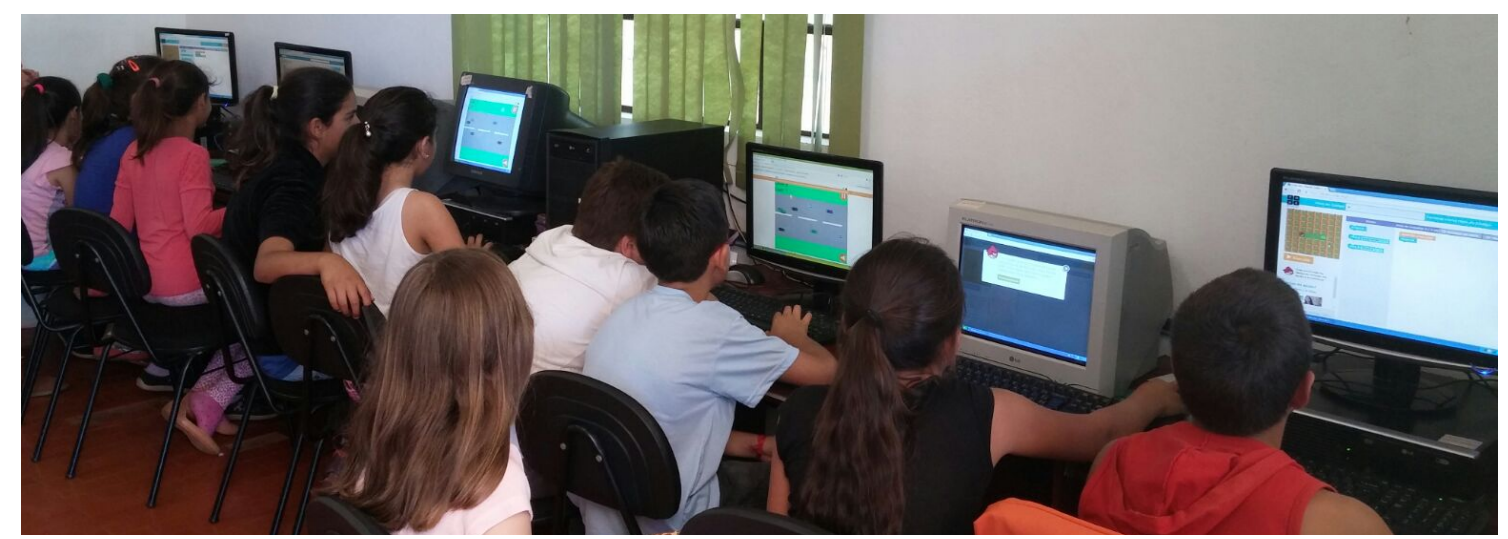

Figura 2. Figura que mostra as crianças da escola da zona rural explorando as ferramentas utilizadas no projeto.

dos alunos com recursos tecnológicos, como computadores em suas casas, celulares e videogames. Constatou-se que aproximadamente $40 \%$ das crianças não tinham computador em casa, mas $62 \%$ indica acessar com frequência a celulares. Quanto às atividades, aproximadamente $63 \%$ relata que acessa a internet frequentemente para jogar e somente $36 \%$ relata que acessa frequentemente a rede mundial de computadores para estudar. A fim de adaptar o nível de dificuldade das atividades que seriam propostas, preparou-se avaliação diagnóstica para aplicação aos discentes. Neste instrumento haviam 10 questões adaptadas do projeto Canguru de Matemática Brasil ${ }^{6}$ do ano 2012, nível PE, que é uma avaliação com questões lógico-matemáticas, recomendada para $3^{\circ}$ e $4^{\circ}$ anos do ensino fundamental.

A Figura 3 mostra que não houve bom rendimento na avaliação, visto que houve alta taxa de erros e/ou não resolução por parte das crianças. Dessa forma, percebeu-se que o grupo demonstrava dificuldades para realização de atividades abstratas, com maior exigência de pensamento lógico. Logo, as atividades a serem desenvolvidas precisavam ser adaptadas ao nível dos alunos.

\subsection{Terceiro e Quarto Encontro}

Nos demais encontros as atividades passaram a ser de caráter prático, explorando o ambiente Scratch. Primeiramente, os alunos exploraram livremente e os monitores demonstraram os comandos básicos de movimentação e mudança de aparência dos personagens. Devido à escassez de computadores, na escola rural os alunos foram divididos em pequenos grupos. Apesar disso notou-se que eles não perderam sua animação, trabalhando de forma colaborativa para a resolução dos problemas propostos.

\section{Pista de Corrida}

Devido interesse do grupo por jogos de corrida e visando ensinar de forma lúdica, conceitos de seleção e repetição, apresentou-se aos alunos uma pista de corrida feita no Scratch que era percorrida automaticamente por um automóvel. Mediante o fascínio das crianças, a equipe informou que eles também poderiam criar animações semelhantes. Assim, foram explicados alguns blocos, sendo salientado o funcionamento dos comandos de repetição e seleção, que tinham sido usados para manipular os objetos do cenário. Na sequência, as crianças começaram a desenvolver a atividade com o auxílio dos monitores. Observou-se

\footnotetext{
${ }^{6}$ Disponível em $\langle\langle$ www.cangurudematematicabrasil.com.br $\rangle>$.
} 


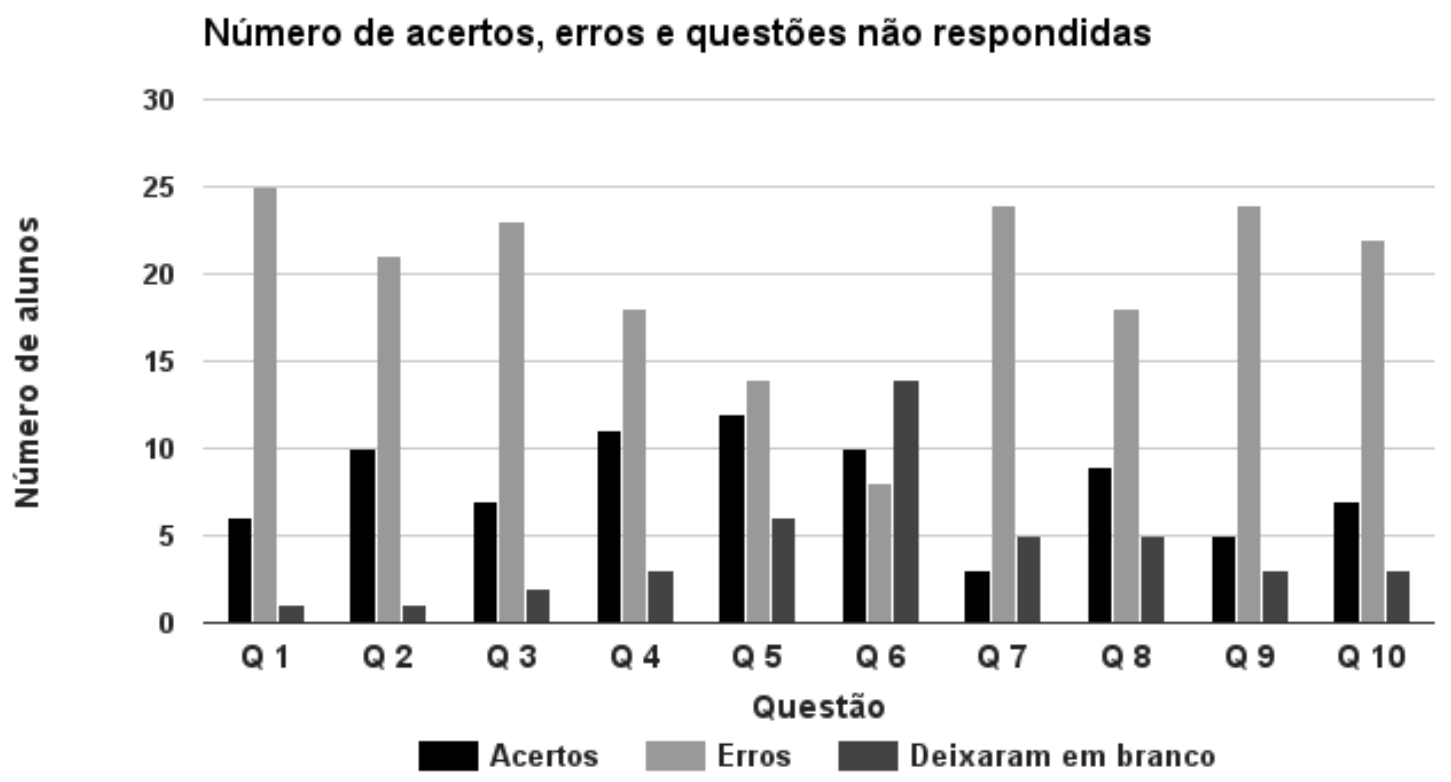

Figura 3. Figura que exibe a relação de erros, acertos e alunos que não responderam as questões da avaliação diagnóstica.

a criatividade das crianças através da variedade de pistas e objetos escolhidos para compor o cenário. Além disso, em diversos momentos os alunos conversavam entre si sobre funcionalidades que poderiam ser usadas.

No quarto encontro o principal tema abordado foi trabalho em grupo. Como alguns alunos não finalizaram o desafio da pista de corridas do encontro anterior, o funcionamento da animação foi explanado, e após relembrarem, as crianças que haviam terminado foram incentivadas a ajudar seus colegas na conclusão da atividade.

\section{Aquário}

Os recursos de desenho foram explorados em atividade para criação de um aquário. As crianças desenharam o cenário e incluíram objetos para animação. Percebeu-se que apesar de terem resolvido a atividade de diferentes maneiras, elas haviam absorvido os conceitos lógicos necessários para resolução do desafio. Assim, após concluírem a pista de corrida e a animação do aquário, em que os objetos se movimentavam de forma automática, os discentes foram parabenizados e instigados a desenvolver exercícios conforme sua imaginação para praticar os comandos aprendidos.

\subsection{Quinto e Sexto Encontro}

Ao estarem mais familiarizadas com o ambiente, as crianças começaram a trabalhar com atividades de perguntas e respostas, criadas por elas, utilizando os recursos de entrada e saída de texto, além de aprenderem o conceito de "variáveis".

\section{Criando Quizzes}

No quinto encontro, as crianças já tinham aprendido vários comandos do Scratch. Portanto, foram propostos exercícios que podiam ser resolvidos de diversas maneiras, visando ampliar a capacidade de tomada de decisões das crianças. Dessa maneira, foram apresentadas variáveis em Scratch. Esse recurso foi ilustrado por um estojo que guardava objetos, 
da mesma maneira que variáveis servem para armazenar informações. A seguir, mostrouse uma animação onde um personagem perguntava o nome da criança e respondia o nome que havia sido digitado. Os discentes foram instruídos que esse tipo de interação poderia ser usada em diversos jogos de perguntas e respostas, chamados quizzes.

Na sequência, os alunos foram instigadas a desenvolver jogos similares, unindo blocos de condição, repetição e variáveis. Por consequência dos exemplos práticos usados para descrever essas funcionalidades, a maioria do grupo não demonstrou dificuldade em utilizar os conceitos de forma conjunta.

\section{Exercitando a criatividade}

O último encontro foi usado para avaliar o crescimento lógico e criativo das crianças. Para isso, os alunos foram aconselhados a criar animações ou jogos com os comandos que eles haviam aprendido no decorrer do projeto.

Nesse sentido, notou-se diversidade nas atividades desenvolvidas. Destacou-se também a interatividade entre as crianças, que discutiam entre si sobre o que poderiam criar, e ao passo que encontravam uma atividade de interesse, aplicavam os conceitos aprendidos para transformar as ideias em algoritmos, conforme ilustrado na Figura 4.

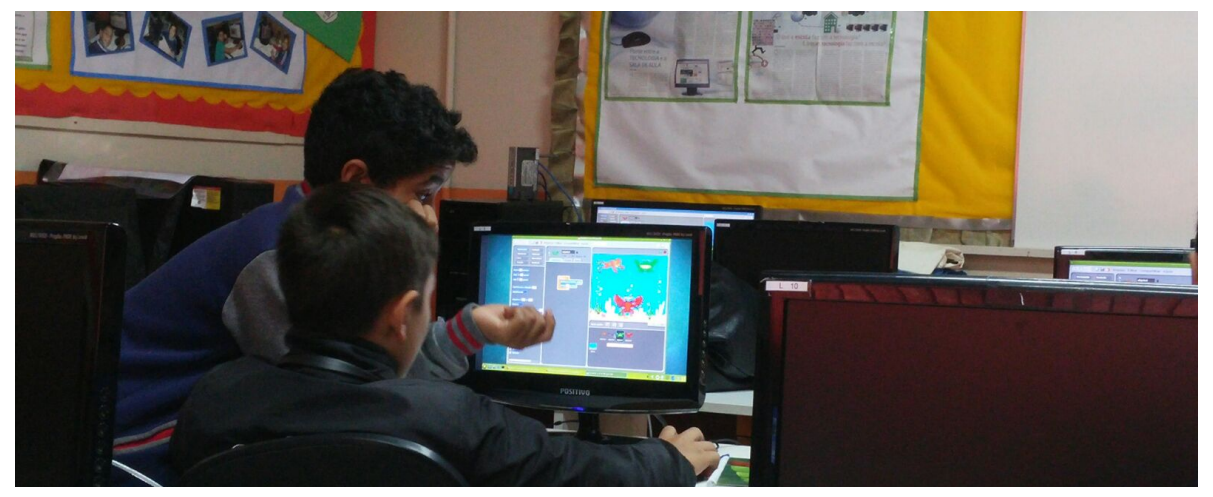

Figura 4. Figura que mostra duas crianças discutindo sobre uma atividade, exemplificando a colaboratividade instigada pelo Design Participativo.

\section{Considerações Finais}

No decorrer do projeto foi constatada a importância da abordagem colaborativa em atividades pedagógicas, pois através da troca de opiniões, os alunos sentiam-se instigados e desinibidos para questionar e sugerir a realização de novas atividades. Além disso, as limitações estruturais dos laboratórios não tiraram o interesse dos alunos, que em diversos momentos tiveram de revezar os computadores para que todos participassem. Outro aspecto percebido ao longo do projeto foi a colaboração, que trouxe vivacidade às aulas, permitindo que as crianças contribuíssem no processo de evolução de seus colegas.

Assim, foi possível perceber o desenvolvimento da habilidade de resolução de problemas dos alunos, que ao final do projeto conseguiram desenvolver diversos jogos e animações de forma autônoma, mostrando domínio das tecnologias ensinadas, independente do contexto inserido, ou seja, tanto na escola rural como na escola urbana. Os professores das instituições onde o projeto foi aplicado expuseram em diversos momentos sua satisfação com as atividades, salientando o entusiasmo dos discentes. Além disso, um 
V Congresso Brasileiro de Informática na Educação (CBIE 2016)

Anais do XXII Workshop de Informática na Escola (WIE 2016)

professor da escola situada na zona rural mostrou interesse na realização de atividades futuras que abordassem novamente a tecnologia como aliada da educação.

Quanto à equipe executora, a experiência foi considerada enriquecedora. No decorrer dos encontros os discentes superaram diversos desafios para desenvolvimento do projeto: a heterogeneidade das turmas, os laboratórios obsoletos, o tempo de aprendizado de cada criança e principalmente, a necessidade de adaptação das atividades previstas. Como trabalhos futuros, recomenda-se o desenvolvimento de práticas educacionais em anos finais do ensino fundamental, explorando novas ferramentas educacionais.

\section{Referências}

BEYNON-DAVIES, P. Information systems development: An introduction to information systems engineering. In: ___. London: Macmillan Education UK, 1998. cap. Participatory Design, p. 273-281. ISBN 978-1-349-14931-5. Disponível em: $\langle$ http://dx.doi.org/10.1007/978-1-349-14931-5\_28〉.

BRASIL. Diretrizes curriculares nacionais para os cursos de graduação em computação. Parecer $n^{o}$ 136/2012. Conselho Nacional de Educação, 2012. Disponível em: $\langle\mathrm{http} / /$ goo.gl/n6ZbMK〉.

CAMPOS, G. M. de et al. Organização de informações via pensamento computacional: Relato de atividade aplicada no ensino fundamental. Anais do Workshop de Informática na Escola, v. 20, n. 1, p. 390, 2014. ISSN 2316-6541. Disponível em: $\langle$ http://br-ie.org/pub/index.php/wie/article/view/3122 .

DUST, F.; JONSDATTER, G. Design dictionary: Perspectives on design terminology. In: . Basel: Birkhäuser Basel, 2008. cap. Participatory Design, p. 290-292. ISBN 9783-7643-8140-0. Disponível em: 〈http://dx.doi.org/10.1007/978-3-7643-8140-0\_192〉.

FONSECA, J. L. e L. C. Educonnect: uma ferramenta de apoio à aprendizagem colaborativa para dispositivos móveis em redes manet. Anais do Simpósio Brasileiro de Informática na Educação, v. 24, n. 1, p. 164, 2013. ISSN 2316-6533. Disponível em: $\langle$ http://br-ie.org/pub/index.php/sbie/article/view/2494〉.

FRANçA, R. de; AMARAL, H. do. Proposta metodológica de ensino e avaliação para o desenvolvimento do pensamento computacional com o uso do scratch. Anais do Workshop de Informática na Escola, v. 1, n. 1, p. 179, 2013. ISSN 2316-6541. Disponível em: 〈http://br-ie.org/pub/index.php/wie/article/view/2646〉.

FURBER, S. Shut down or restart? the way forward for computing in uk schools. The Royal Society, London, 2012.

LEE, I. et al. Computational thinking for youth in practice. Acm Inroads, ACM, v. 2, n. 1, p. 32-37, 2011.

LUCENA, M. G. e Hugo Fuks e C. Suporte à percepção em ambientes de aprendizagem colaborativa. Revista Brasileira de Informática na Educação, v. 11, n. 2, p. 75-85, 2012. ISSN 1414-5685. Disponível em: 〈http://br-ie.org/pub/index.php/rbie/article/view/2200〉.

MOMBACH, J. et al. Gurizada.net: Inclusão digital em perspectiva participativa. Anais do Workshop de Informática na Escola, v. 1, n. 1, p. 1069-1078, 2010. ISSN 2316-6541. Disponível em: 〈http://br-ie.org/pub/index.php/wie/article/view/2029〉. 
V Congresso Brasileiro de Informática na Educação (CBIE 2016)

Anais do XXII Workshop de Informática na Escola (WIE 2016)

MOTA, F. P. et al. Desenvolvendo o raciocínio lógico no ensino médio: uma proposta utilizando a ferramenta scratch. Anais do Simpósio Brasileiro de Informática na Educação, v. 25, n. 1, p. 377, 2014. ISSN 2316-6533. Disponível em: 〈http://br-ie.org/pub/index.php/sbie/article/view/2964〉.

NOBRE, R.; SOUSA, J. D.; NOBRE, C. Uso dos laboratórios de informática em escolas do ensino médio e fundamental no interior nordestino. Revista Brasileira de Informática na Educação, v. 23, n. 03, p. 68, 2015. ISSN 1414-5685. Disponível em: 〈http://br-ie.org/pub/index.php/rbie/article/view/2882〉.

RAMOS, D. Processos colaborativos mediados pelo computador e as contribuições da teoria da atividade. Revista Brasileira de Informática na Educação, v. 18, n. 03, p. 34, 2011. ISSN 1414-5685. Disponível em: 〈http://br-ie.org/pub/index.php/rbie/article/view/ $1257\rangle$.

RAMOS, F.; TEIXEIRA, L. Significação da aprendizagem através do pensamento computacional no ensino médio: uma experiência com scratch. Anais do Workshop de Informática na Escola, v. 21, n. 1, p. 217, 2015. ISSN 2316-6541. Disponível em: $\langle$ http://br-ie.org/pub/index.php/wie/article/view/5024〉.

RODRIGUEZ, C. et al. Pensamento computacional: transformando ideias em jogos digitais usando o scratch. Anais do Workshop de Informática na Escola, v. 21, n. 1, p. 62, 2015. ISSN 2316-6541. Disponível em:〈http://br-ie.org/pub/index.php/wie/article/view/ 4992>.

VIEIRA, A. S. S. e Adolfo Duran e V. Um estudo de mapeamento sistemático sobre ontologias para a metodologia de aprendizagem baseada em problemas. Anais do Simpósio Brasileiro de Informática na Educação, v. 25, n. 1, p. 1103, 2014. ISSN 2316-6533. Disponível em: 〈http://br-ie.org/pub/index.php/sbie/article/view/3055〉.

Von Wangenheim, C. G.; NUNES, V. R.; SANTOS, G. dos. Ensino de computação com scratch no ensino fundamental - um estudo de caso. Revista Brasileira de Informática na Educação, v. 22, n. 03, p. 115, 2014. ISSN 1414-5685. Disponível em: $\langle$ http://br-ie.org/pub/index.php/rbie/article/view/2885〉.

WING, J. M. Computational thinking. Communications of the ACM, v. 49, n. 3, p. 33-35, 2006. 